\title{
Loss of expression of DNA repair enzymes MGMT, hMLH1, and hMSH2 during tumor progression in gastric cancer
}

\author{
Yoshiniko Kitajima ${ }^{1}$, Kohj Miyazaki $^{1}$, Shiroh Matsukura $^{1}$, Masayuki Tanaka ${ }^{1}$, and Mutsuo Sekiguchi ${ }^{2}$ \\ ${ }^{1}$ Department of Surgery, Saga Medical School, 5-1-1 Nabeshima, Saga 849-0937, Japan \\ ${ }^{2}$ Biomolecular Engineering Research Institute, Osaka, Japan
}

\begin{abstract}
Background. Disorders of the DNA repair system that protects against alkylating mutagens are known to play an important role in carcinogenesis.

Methods. We investigated the expression of the DNA repair enzyme that protects against alkylating mutagens, $\mathrm{O}^{6}$ methylguanine DNA methyltransferase (MGMT), and the mismatch repair (MMR) enzymes, hMLH1 and hMSH2, in 135 gastric cancer specimens by immunohistochemical means. Results. The immunoreactivity of MGMT and MMR proteins correlated significantly with several clinicopathologic factors. The survival curve in 116 patients showed that a loss of MGMT or hMLH1, but not of hMSH2, correlated with a poor prognosis. Combined evaluation of MGMT and hMLH1 revealed that the survival of patients with negative status for both MGMT and hMLH1 was shortest. However, this significant association between patient survival and MGMT or hMLH1 expression disappeared when early and advanced cancers were separately analyzed, indicating that synchronous losses of MGMT and hMLH1 increase during tumor progression and stage. Further evaluation according to histologic type revealed that loss of MGMT, hMLH1, and hMSH2 expression significantly differed between early and advanced cancer in differentiated-type cancers. In contrast, in undifferentiatedtype cancer, loss of MGMT and MMR expression was frequently found even in intramucosal (m) cancer, and no significant difference was found in loss of hMLH1 and hMSH2 between early and advanced cancer.

Conclusion. These findings demonstrate that the reduced expression of MGMT, hMLH1, and hMSH2 in differentiatedtype cancer may play an important role during tumor progression between the early and advanced stage. On the other hand, in undifferentiated-type cancer, loss of MGMT and the MMR proteins appears to be an important event at carcinogenesis or at an earlier step of tumor progression.
\end{abstract}

Key words MGMT $\cdot$ hMLH1 $\cdot$ hMSH2 $\cdot$ Gastric cancer

Offprint requests to: K. Miyazaki

Received: October 15, 2002 / Accepted: January 7, 2003

\section{Introduction}

An accumulation of multiple alterations in oncogenes and tumor suppressor genes participates in carcinogenesis and the progression of gastric cancer [1-3]. Gene abnormalities also differ in accordance with the histologic type of this malignancy [1]. However, the mechanism through which the multiple gene mutations accumulate during carcinogenesis or tumor progression in gastric cancer is not well understood.

Alkylating mutagens that are either externally administered or produced through endogenous metabolic pathways lead to chemical modifications of cellular DNA [4]. $\mathrm{O}^{6}$-Methylguanine formed on DNA strands after exposure to alkylating substances appears to be responsible for the induction of gene mutation. Subsequent gene mutations triggered by $\mathrm{O}^{6}$-methylguanine on DNA strands may accumulate and result in the development of cancer [4]. In fact, gastric carcinoma is induced in rats by the alkylating mutagen N-methyl-N'nitro-N-nitroguanidine (MNNG). This in vivo procedure is an established model of carcinogenesis in human stomach cancer [5].

$\mathrm{O}^{6}$-Methylguanine DNA methyltransferase (MGMT) is a repair enzyme that protects against alkylating carcinogens such as methylnitrosourea (MNU) [6]. MGMT transfers a methyl group from $\mathrm{O}^{6}$-methylguanine produced by $\mathrm{MNU}$, (which leads to a G:C-A:T transition on DNA) to a cysteine residue of the MGMT molecule itself [4]. Thus, MGMT protects against gene mutation caused by alkylating agents, and a loss of MGMT expression is thought to bring about gene mutation and lead to the development of cancer.

The mismatch repair (MMR) system is required for the cell to accurately copy its genome during cellular proliferation. Deficiencies of this system result in mutation rates 100 -fold greater than those observed in normal cells [7]. These mutations are particularly evident at microsatellite sequences, consisting of repeats of $1-4 \mathrm{bp}$. 
Microsatellite instability (MSI) is thereby a hallmark of MMR gene-deficient cancers [7]. Especially, hereditary nonpolyposis colorectal cancer (HNPCC) is associated with germline mutations in two MMR genes, $h M L H 1$ and $h M S H 2[8,9]$.

Transgenic mice defective in the MGMT gene have been analyzed with respect to DNA alkylation-induced tumorigenesis. MGMT-knockout mice developed thymic lymphoma or lung adenoma after exposure to a low level of MNU, demonstrating that the absence of $M G M T$ induces tumor development in vivo under these conditions. However, the administration of high doses of MNU to such mice caused death of the animals due to apoptosis of rapidly growing cells in certain organs, such as the bone marrow [10,11]. When the additional loss of the $h M L H 1$ gene was introduced into MGMTdeficient mice, this myelosuppression disappeared, while the number of thymic lymphomas significantly increased [12]. Thus, an additional loss of the MMR system would prevent $M G M T$-single-knockout mice from death caused by an alkylating agent.

These results prompted us to investigate the effect of loss of these DNA repair proteins in the tumor progression of gastric cancer. We immunohistochemically analyzed the expression levels of MGMT and the MMR enzymes, hMLH1 and hMSH2, in 135 resected gastric cancer specimens at various tumor stages. We asked whether or not loss of the MGMT and MMR enzymes was related to clinicopathologic factors and patient survival. We also examined whether levels of the DNA repair system that protects against alkylating mutagens change through tumor progression and whether these changes are related to histologic types of gastric carcinoma.

\section{Patients and methods}

\section{Tumor specimens}

A total of 135 consecutive formalin-fixed, paraffinembedded gastric carcinoma specimens were obtained from the archival tissue bank of the Pathology Department at Saga Medical School, Saga, Japan (the patients had undergone gastrectomy between January 1989 and July 1995 for early cancer, and between 1989 and 1991 for advanced cancer). All of the specimens were examined macroscopically and histologically according to the criteria of the Japanese classification of gastric carcinoma [13]. The specimens were classified into two histologic groups: (a) differentiated-type cancer, including papillary adenocarcinoma and well- and moderately differentiated tubular adenocarcinoma, which were roughly consistent with intestinal-type cancer by Lauren's classification [14] and (b) undifferentiated- type cancer, consisting of poorly differentiated adenocarcinoma and signet-ring cell carcinoma, which were identical to diffuse-type cancer [14].

All 135 tumors were also classified into two groups according to depth of tumor invasion: 88 were categorized as early gastric cancer, consisting of 45 intramucosal carcinomas ( $m$ cancer) and 43 that had invaded the submucosal layer (sm cancer). The remaining 47 tumors were classified as advanced carcinoma, that had invaded beyond the muscularis propria $(\mathrm{mp}$ and more advanced cancer) [13]. A section from each specimen block was stained with hematoxylin and eosin for histological evaluation, and representative blocks were immunostained. Normal gastric mucosa adjacent to the tumor was used as an internal control for normal nuclear staining of the MGMT and MMR enzymes.

\section{Antibodies and immunohistochemical staining}

Rabbit polyclonal MGMT antibody was provided by Dr. Y. Nakabeppu (Kyushu University). The immunospecificity of this antiserum has been confirmed in recent studies $[15,16]$. Mouse monoclonal hMLH1 and hMSH2 antibodies were purchased from PharMingen (San Diego, CA, USA). Appropriate antibody dilutions were determined by serial titration in the presence of positive and negative controls. The final dilutions of MGMT, hMLH1, and hMSH2 antibodies were 1:200, $1: 100$, and $1: 100$, respectively.

Formalin-fixed, paraffin-embedded tissue blocks were cut into $4-\mu \mathrm{m}$-thick sections for immunostaining. The sections were dewaxed using xylene and transferred to alcohol. Antigen was retrieved as previously described [15]. To reduce nonspecific background staining, the sections were immersed in $10 \%$ normal goat serum for $10 \mathrm{~min}$ at room temperature. After being washed in phosphate-buffered saline (PBS), the sections were incubated overnight with the primary antibodies (in PBS containing 1\% bovine serum albumin) at $4^{\circ} \mathrm{C}$ in a humidified chamber. The sections were then washed in PBS and incubated with goat anti-rabbit or anti-mouse IgG conjugated to peroxidase labelleddextran polymer (Dako Envision+TM; Dako, Carpinteria, CA, USA) for $30 \mathrm{~min}$. After further washing in PBS, the sections were developed with activated 3, 3'-diaminobenzidine-tetrahydrochloride (DAB) for $5 \mathrm{~min}$, and the reaction was stopped in water. Nuclei were visualized by counter-staining with Meyer's hematoxylin. Immunohistochemical reactivity was determined independently by three investigators (Y.K., M.T., and G.E.). Expression levels of the MHMT, $h M L H 1$, and $h M S H 2$ genes were evaluated by counting the number of nuclear-stained cancer cells in five fields, which were randomly selected. Finally, immunopositivity was assessed as the mean percentage of positive 
cells counted in the five fields. When over $30 \%$ of the nuclei of cancer cells were stained, expression was judged as positive.

\section{Statistical analysis}

Results were statistically analyzed using the $\chi^{2}$ test. Differences among groups were determined using Student's $t$-test. The survival curve of patients was determined according to the Kaplan-Meier method. The significance of differences in survival between two groups was tested using the Breslow-Gehan-Wilcoxon test. StatView-5.0 software (SAS Institute, Cary, NC, USA) was used to perform all statistical analyses. A value of $P<0.05$ was considered statistically significant.

\section{Results}

Immunohistochemical staining of MGMT, hMLH1, and $h M S H 2$ proteins

MGMT, and the MMR enzymes, hMLH1 and hMSH2, were intensely expressed in the nuclei of cancer cells and were also detected in normal epithelia. MGMT, hMLH1, and hMSH2 were immunopositive in $62.2 \%$ (84/135), $63.7 \%(86 / 135)$, and $67.4 \%(91 / 135)$ of specimens, respectively. Figure 1 shows the immunohistochemical staining of MGMT, hMLH1, and hMSH2 in gastric adenocarcinoma. MGMT-positive staining was evident in the nuclei of a differentiated-type cancer specimen (Fig. 1a), while in another specimen of differentiated-type cancer there were no stained cells (Fig. 1b). Figure 1c,d shows positive nuclear staining of hMLH1 found in normal gastric epithelial cells and differentiated-type cancer cells. Figure 1e,f shows positive and negative staining for hMSH2 in nuclei of undifferentiated-type carcinomas.

\section{Correlation between clinicopathologic factors and expression of DNA repair enzymes}

Table 1 shows comparisons of MGMT, hMLH1, and hMSH2 expressions with clinicopathologic factors in 135 patients with gastric cancer. Differences in MGMT expression level were significant with respect to tumor size $(P=0.0001)$, depth of wall invasion $(\mathrm{t} ; P<0.0001)$, histologic type $(P<0.0001)$, metastasis to regional lymph nodes (n; $P=0.0064)$, invasion of lymphatic (ly; $P=0.0005)$ and venous vessels $(\mathrm{v} ; P=0.0024)$, and tumor stage $(P<0.0001)$.

The MMR proteins, hMLH1 and hMSH2, were also compared in similar ways. The expression of hMLH1 was closely correlated with the clinicopathologic factors, such as tumor size $(P<0.0001)$, t $(P<0.0001)$, histologic type $(P=0.0002), \mathrm{n}(P=0.0012)$, ly $(0.019)$, and stage $(P<0.0001)$. The association of hMSH2 expression was significant with age $(P=0.03)$, tumor size $(P=0.005), \mathrm{t}(0.017)$, and histologic type $(P=0.0056)$, whereas the association between hMSH2 immunoreactivity and $\mathrm{n}$, ly, v, and stage was not statistically significant. We analyzed association of the immunoreactivity among the MGMT, hMLH1, and hMSH2 proteins. Immunoreactivity for MGMT and hMLH1 was closely correlated $(P<0.0001)$ in the 135 specimens. Immunoreactivity for MGMT and hMSH2 expression was also correlated, $(P=0.026)$, but to a lesser extent than that for MGMT and hMLH1.

\section{Patient survival relative to expression of MGMT or MMR enzymes}

The relationship between postoperative survival and MGMT, hMLH1, or hMSH2 status was analyzed in 116 patients (77 with early and 39 with advanced cancers), who could be followed up.

Among the 116 patients, the prognosis of those with negative MGMT expression was poorer than that of those with positive expression (Fig. $2 ; P=0.0004$ ). Survival in hMLH1-negative patients was also significantly worse than that in-positive patients overall (Fig. 2; $P=$ 0.022 ). However, the differences between positive and negative MGMT and hMLH1 status and patient survivals were not significant on Kaplan-Meier curves when the same analysis was separately applied to the 77 patients with early and the 39 with advanced cancer (Fig. 2). A multivariate analysis using Cox proportional hazards regression models revealed that neither MGMT nor hMLH1 status was an independent factor for the survival of patients with gastric cancer (data not shown). The hMSH2 status did not affect postoperative survival in the patients overall, or in the 77 patients with early cancer or the 39 patients with advanced cancers.

\section{Loss of MGMT and MMR enzymes according to histologic type of carcinoma}

Table 1 shows that there were significant differences in MGMT and MMR expression between the two histologic types of carcinoma. The loss of MGMT and MMR expression was more frequent in undifferentiated cancers, as compared with differentiated-type cancers. Furthermore, the proportion of negative staining for MGMT, hMLH1, and hMSH2 increased significantly from early ( $\mathrm{m}$ and sm cancer) to advanced cancers ( $\mathrm{mp}$ and more advanced cancer). Thus, we investigated whether MGMT, hMLH1, and hMSH2 status in the two histologic types varied according to depth of invasion (Tables 2, 3, 4). In the differentiated type of gastric cancer, the "early" group ( $\mathrm{m}$ and sm cancer) exhibited a $12.5 \%(8 / 64)$ negative rate for MGMT expression, 


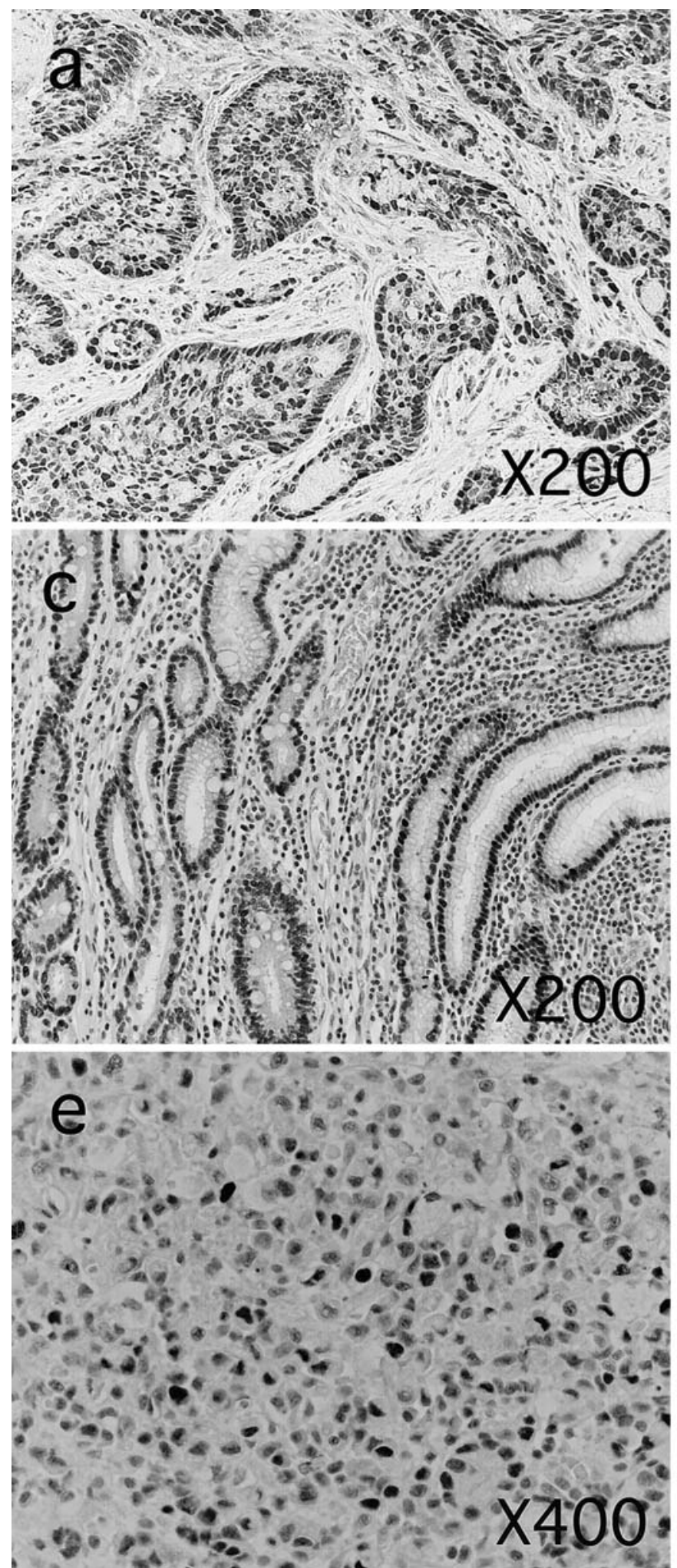

Fig. 1a-f. Immunohistochemical staining of MGMT, hMLH1, and hMSH 2 proteins in gastric adenocarcinoma. a Tumor cells show strong nuclear accumulation of MGMT in a specimen of differentiated-type cancer. b Immunostaining of MGMT was judged negative in another specimen of differentiated-type cancer. c Normal gastric epithelium shows strong nuclear

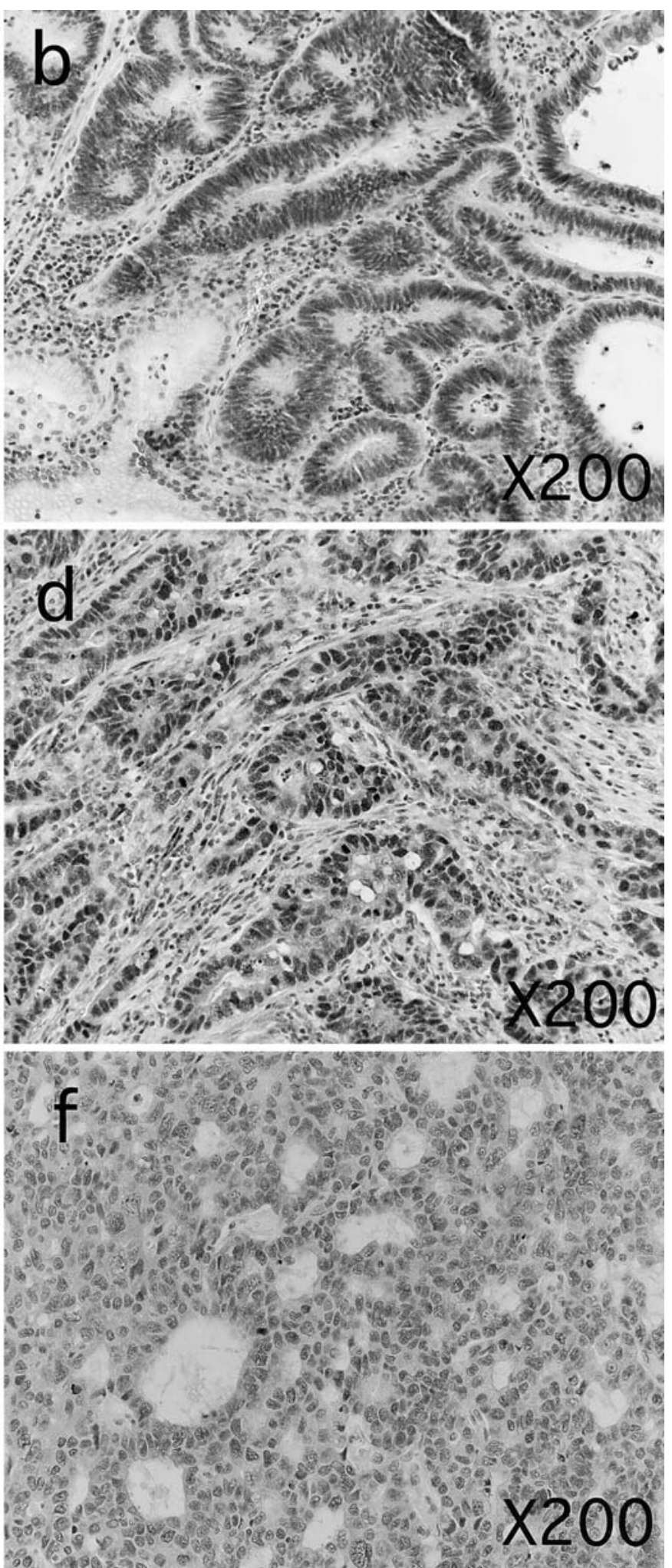

staining of hMLH1. d Nuclear staining of hMLH1 was also detected in a specimen of differentiated-type cancer. e Positive nuclear staining of hMSH2 protein was shown in a specimen of undifferentiated-type cancer. f Negative staining of hMSH2 was found in another specimen of undifferentiatedtype cancer 


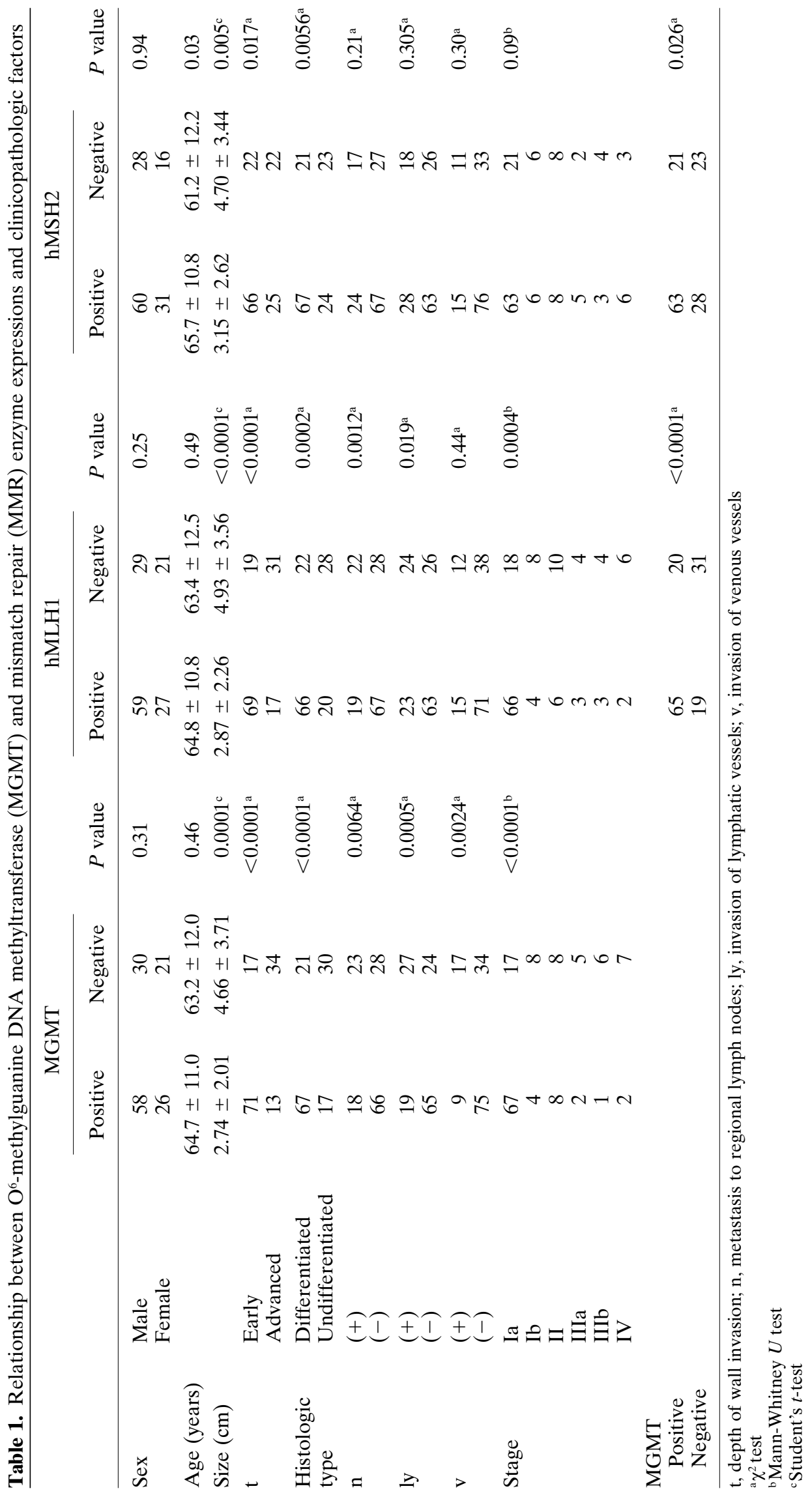



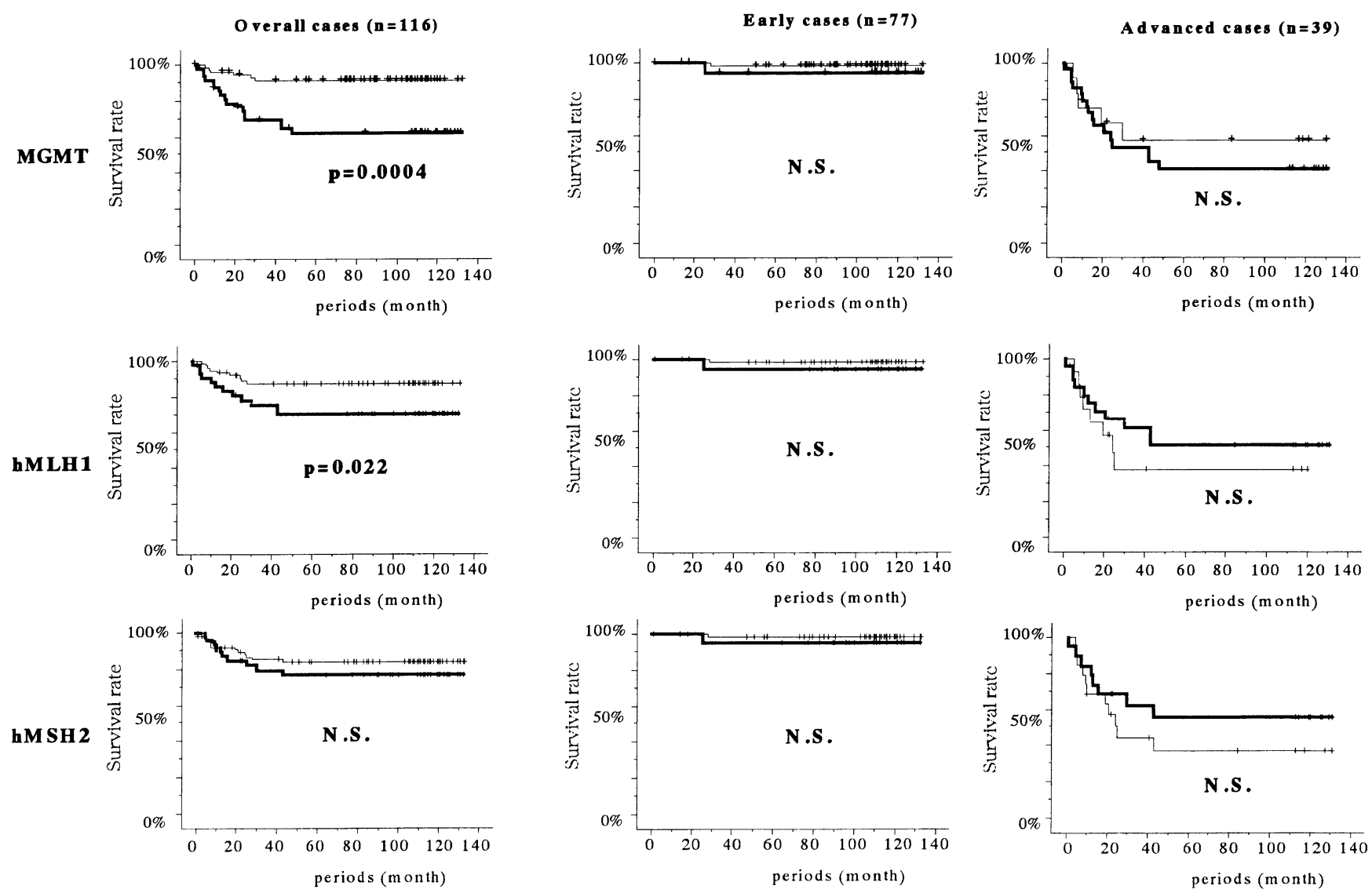

Fig. 2. Kaplan Meier curves in 116 patients with gastric cancer for whom postoperative survival could be followed up. Postoperative survival rates are shown in the 116 patients overall, and in the 77 early, and 39 advanced gastric cancer patients, according to the expressions of MGMT, hMLH1, and hMSH2. N.S. not significant. Thin lines, positive expression; thick line, negative expression

Table 2. Alteration of MGMT expression during tumor progression

\begin{tabular}{|c|c|c|c|c|c|}
\hline & & \multicolumn{2}{|c|}{ MGMT status } & \multirow{2}{*}{$\begin{array}{c}\text { Negative } \\
\text { rate }\end{array}$} & \multirow[b]{2}{*}{$P$ value } \\
\hline & & Positive & Negative & & \\
\hline \multicolumn{6}{|c|}{ Differentiated carcinoma } \\
\hline \multirow[t]{2}{*}{ Early } & $\mathrm{m}$ & $28(56)$ & $7(8)$ & $12.5 \%$ & \multirow{6}{*}{0.0001} \\
\hline & $\mathrm{sm}$ & 27 & 1 & & \\
\hline \multirow[t]{4}{*}{ Advanced } & $\mathrm{mp}$ & $1(11)$ & $2(13)$ & \multirow[t]{4}{*}{$54.2 \%$} & \\
\hline & ss & 8 & 8 & & \\
\hline & se & 1 & 3 & & \\
\hline & si & 1 & 0 & & \\
\hline \multicolumn{6}{|c|}{ Undifferentiated carcinoma } \\
\hline \multirow[t]{2}{*}{ Early } & $\mathrm{m}$ & $5(15)$ & $5(9)$ & $37.5 \%$ & \multirow{6}{*}{$<0.0004$} \\
\hline & $\mathrm{sm}$ & 10 & 4 & & \\
\hline \multirow[t]{4}{*}{ Advanced } & $\mathrm{mp}$ & $1(2)$ & $4(21)$ & \multirow{4}{*}{$91.3 \%$} & \\
\hline & ss & 0 & 5 & & \\
\hline & se & 1 & 11 & & \\
\hline & si & 0 & 1 & & \\
\hline
\end{tabular}

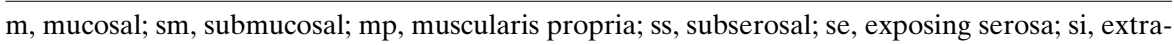
serosal invasion 
Table 3. Alteration of hMLH1 expression during tumor progression

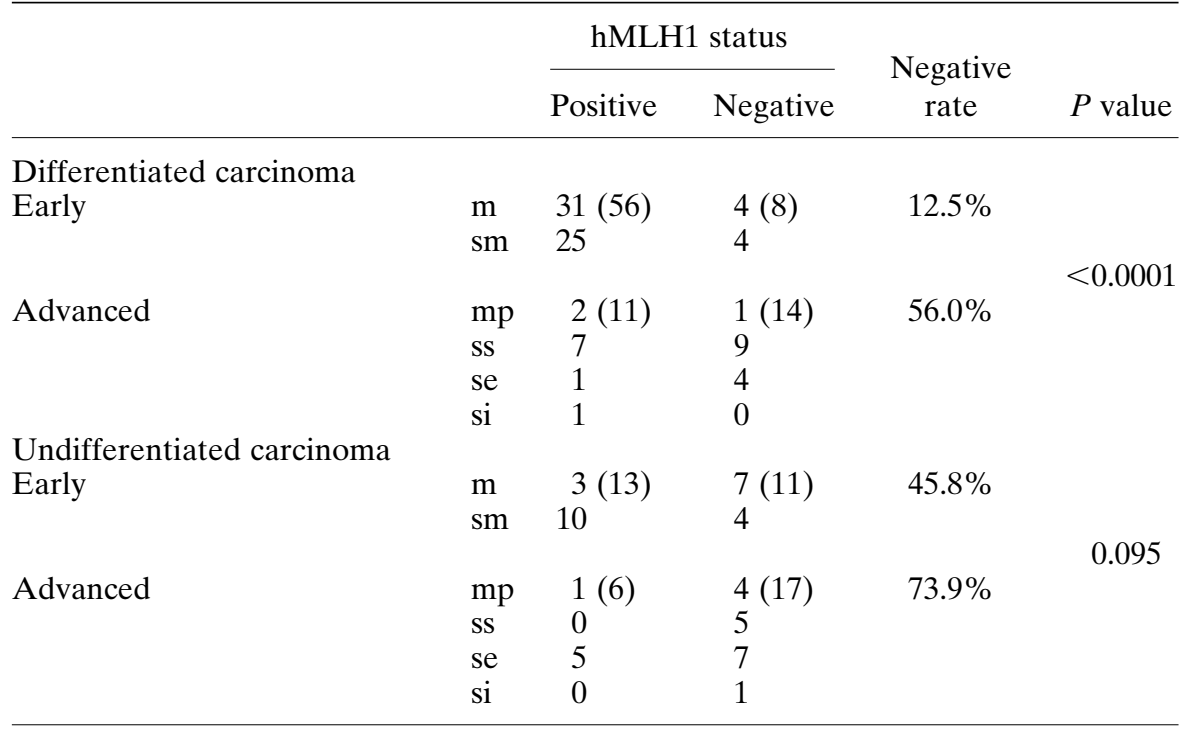

Table 4. Alteration of hMSH2 expression during tumor progression

\begin{tabular}{|c|c|c|c|c|c|}
\hline & & \multicolumn{2}{|c|}{ hMSH2 status } & \multirow{2}{*}{$\begin{array}{l}\text { Negative } \\
\text { rate }\end{array}$} & \multirow[b]{2}{*}{$P$ value } \\
\hline & & Positive & Negative & & \\
\hline \multicolumn{6}{|c|}{ Differentiated carcinoma } \\
\hline \multirow[t]{2}{*}{ Early } & $\mathrm{m}$ & $31(54)$ & $4(11)$ & $16.9 \%$ & \multirow{6}{*}{0.034} \\
\hline & $\mathrm{sm}$ & 23 & 7 & & \\
\hline \multirow[t]{4}{*}{ Advanced } & $\mathrm{mp}$ & $3(14)$ & $0(10)$ & \multirow[t]{4}{*}{$41.7 \%$} & \\
\hline & ss & 8 & 8 & & \\
\hline & se & 2 & 2 & & \\
\hline & si & 1 & 0 & & \\
\hline \multicolumn{6}{|c|}{ Undifferentiated carcinoma } \\
\hline \multirow[t]{2}{*}{ Early } & $\mathrm{m}$ & $4(12)$ & $6(11)$ & $47.8 \%$ & \multirow{6}{*}{0.88} \\
\hline & $\mathrm{sm}$ & 8 & 5 & & \\
\hline \multirow[t]{4}{*}{ Advanced } & $\mathrm{mp}$ & $1(11)$ & $4(12)$ & \multirow[t]{4}{*}{$52.2 \%$} & \\
\hline & ss & 2 & 3 & & \\
\hline & se & 7 & 5 & & \\
\hline & si & 1 & 0 & & \\
\hline
\end{tabular}

whereas the negative rate was $54.2 \%$ (13/24) for the advanced group (i.e., mp, subserosal [ss], exposing serosa [se], and extraserosal invasion [si] cancers; Table $2)$. The difference was statistically significant $(P=$ 0.0001). In undifferentiated cancers, MGMT staining was negative in $37.5 \%(9 / 24)$ at the early stage, and the proportion significantly increased to $91.3 \%(21 / 23)$ at the advanced stage $(P<0.0004)$.

With respect to hMLH1 status, the difference in the immunoreactivity between early (negative rate, $12.5 \%$ [8/64]) and advanced stage (negative rate, 56\% [14/25]) in differentiated-type cancer was also significant $(P<$ 0.0001). However, the difference between early and advanced cancer in the undifferentiated type was not significant; the negative rate was $45.8 \%$ (11/24) for the early and $73.9 \%(17 / 23)$ for the advanced cancers $(P=0.095,>0.05 ;$ Table 3$)$. Finally, the negative rate for hMSH2 in differentiated-type cancer differed significantly between early and advanced cancer. The negative rates were $16.9 \%(11 / 65)$ in early and $41.7 \%$ $(10 / 24)$ in advanced stages $(P=0.034)$. However, the significance disappeared in undifferentiated-type cancer, where the negative rates for hMSH2 were $47.8 \%$ $(11 / 23)$ in early and $52.2 \%(12 / 23)$ in advanced cancers ( $P=0.88$; Table 4).

An evaluation focusing on 45 specimens of $m$ cancer demonstrated that the negative rates of MGMT, hMLH1, and hMSH2 expression in 10 undifferentiated- 
type cancers were $50 \%$ (5 of 10 ), $70 \%$ (7 of 10 ), and $60 \%$ (6 of 10). All rates were much lower in differentiated-type cancer, where the negative rates were $20 \%$ ( 7 of 35 ), $11.4 \%$ ( 4 of 35 ), and $11.4 \%$ ( 4 of 35 ), respectively (Tables $2,3,4$ ).

\section{Discussion}

We have recently reported that a reduction of MGMT expression in several cancer tissues, including hepatocellular, gastric, breast, and biliary tract carcinoma, correlated with several clinicopathologic factors and poorer prognosis in the patients $[15,16]$.

Immunohistochemical studies of hMLH1/hMSH2 have also been reported for several sporadic cancers, including colorectal, gastric, endometrial, and ovarian carcinomas [17-22]. However, few reports have demonstrated correlations between the immunohistochemical status of MMR proteins and clinicopathologic factors and patient prognosis in gastric cancer. It has been reported that colorectal cancer patients with hMLH1negative expression showed worse prognoses than those with hMLH1/hMSH2-positive tumors, although the difference was not statistically significant [23].

The present study addressed the immunohistochemical evaluation of MGMT and MMR status in gastric cancer specimens at early and advanced stages. In particular, we investigated the relationship of MGMT and MMR expression to tumor progression and histologic type. The correlation between MGMT expression loss in relation to that of MMR and clinicopathologic factors was evaluated in 135 patients with gastric cancer overall. We showed that loss of MGMT and MMR expression significantly correlated with several factors, including tumor size, depth of wall invasion, histologic type, and stage. Immunoreactivity for MGMT and hMLH1 expression was closely correlated in all 135 specimens $(P<0.0001)$. These findings demonstrate that loss of MGMT and hMLH1 may be synchronously accelerated during tumor progression. The postoperative survival curves for the 116 patients who were followed up showed that those without MGMT or hMLH1 expression had poorer prognoses than those patients who expressed these proteins. The differences in survival are thought to reflect the fact that the negative rate of expression of MGMT and hMLH1 increased during tumor progression.

We further investigated whether the loss of MGMT and MMR expression differed between differentiatedand undifferentiated-type cancers. We examined loss of these enzymes at various depths of cancer invasion in the two histologic types. Tables 2, 3, and 4 show that the percent loss of MGMT, hMLH1, and hMSH2 expression in differentiated-type cancers increased from early to advanced cancer $(P=0.0001, P<0.0001$, and $P=$ 0.034 , respectively). These findings indicate that, in differentiated-type cancer, the loss of MGMT, hMLH1, and $\mathrm{hMSH} 2$ expression is critical for the early stage to proceed to an advanced stage. In undifferentiated-type cancer, the difference in expression loss of hMLH1 and hMSH2 between early and advanced cancer was not significant $(P=0.095$ and $P=0.88$, respectively), whereas the expression loss of MGMT differed significantly between early (37.5\%) and advanced carcinoma $(91.3 \% ; P=0.0004)$. In our examination limited to $\mathrm{m}$ cancer, the negative rates of MGMT, hMLH1, and $\mathrm{hMSH} 2$ in the undifferentiated type were much higher than those in differentiated-type cancer. These findings suggest that loss not only of MMR proteins but also of MGMT occurs predominantly at an earlier step of tumor progression or carcinogenesis in undifferentiatedtype cancers, rather than at progression from early to advanced cancer.

Cancer with a high frequency of MSI is thought to express the DNA replication error (RER) phenotype caused by the inactivation of MMR genes, including $h M L H 1$ and $h M S H 2$ [7-9]. Oliveira et al. [24] demonstrated that the RER phenotype in 152 gastric cancer specimens was found more frequently in intestinal-type than in diffuse-type cancer, and the phenotype was closely associated with a low pTNM stage, resulting in a significantly better prognosis. These findings showed clear discrepancies compared with our results. We showed survival curves for 116 patients overall, 77 patients with early gastric cancer, and 39 patients with advanced gastric cancer, separately investigated. In the survival of the 116 patients overall, patients with loss of hMLH1, suggesting MSI $(+)$, had a poorer prognosis than those who were positive for hMLH1 expression. In the 39 patients with advanced gastric cancer, however, MMR-positive patients exhibited a tendency toward a poorer prognosis, though the difference was not significant. This result may be consistent with the previous report, in which 136 of the 152 patients had advanced gastric cancer [24]. We also showed more frequent loss of MMR proteins in undifferentiated-type cancer than in the differentiated type. Eearlier loss of MMR protein was found in undifferentiated-type cancer compared with differentiated cancer. This result may suggest that a higher frequency of MSI was present in undifferentiated-type cancer. However, the previous reports demonstrated a significant association between MSI (+) and intestinal (differentiated), not diffuse (undifferentiated)-type gastric cancer [24,25]. At present, for undifferentiated-type cancer, it is not possible to explain the discrepancy between the frequent loss of MMR proteins found in the present study and the rare occurrence of MSI $(+)$ as previously demonstrated $[24,25]$. 
Recently, several investigators have reported that $\mathrm{CpG}$ islands on promoters of the MGMT and $h M L H 1$ genes, but not those of the $h M S H 2$ gene, are hypermethylated in several malignancies, and that aberrant hypermethylation represses the expression of MGMT and hMLH1. [26-37]. Hypermethylation on the MGMT and $h M L H 1$ promoters might occur concurrently, which could lead to a loss of the protein expression along with tumor progression in gastric cancer. Environmental alkylating agents, such as N-nitroso compounds, are endogenously metabolized and activated in hepatocytes $[38,39]$. MNU is also formed in the lumen of the human stomach after the consumption of fish sauce [40]. These reports indicate that the gastric mucosa is always environmentally exposed to alkylating mutagens. Although it is not possible to elucidate why the loss of MGMT and hMLH1 correlates with tumor progression in gastric cancer, one hypothesis may be advanced. Expression losses of MGMT and hMLH1 may easily render G:C to A:T mutations on cellular DNA exposed to alkylating mutagens, and gene mutations affecting carcinogenesis, invasion, and metastasis may accumulate, resulting in tumor progression with more malignancy.

We conclude that the expression of MGMT and the MMR proteins, hMLH1 and hMSH2, may be lost during the tumor progression of gastric cancer. The losses of these proteins from early to advanced cancer were typically observed in differentiated-type gastric cancer. We also showed that the onset of negative expression of MGMT, as well as that of the MMR proteins, hMLH1 and hMSH2, may differ between the two histologic types of this malignancy.

Acknowledgment The authors thank Dr. Genichirou Edakuni for his excellent technical assistance and histological assessments.

\section{References}

1. Tahara E. Genetic alterations in human gastrointestinal cancers. Cancer 1995;75(Suppl):1411-7.

2. Yasui W, Yokozaki H, Fujimoto J, Naka K, Kuniyasu H, Tahara E. Genetic and epigenetic alterations in multistep carcinogenesis of the stomach. J Gastroenterol 2000;35:111-5.

3. Correa P, Shiao YH. Phenotypic and genotypic events in gastric carcinogenesis. Cancer Res 1994;54:1941-3.

4. Ito T, Nakamura T, Maki H, Sekiguchi M. Roles of transcription and repair in alkylating mutagenesis. Mutat Res 1994;314:27385.

5. Engelbergs J, Thomale J, Rajewsky MF. Role of DNA repair in carcinogen-induced ras mutation. Mutat Res 2000;450:139-53.

6. Sekiguchi M, Nakabeppu Y, Sakumi K, Tsuzuki T. DNA-repair methyltransferase as a molecular device for preventing mutation and cancer. J Cancer Res Clin Oncol 1996;122:199-206.

7. Prolla TA, Abuin A, Bradley A. DNA mismatch repair deficient mice in cancer research. Cancer Biology 1996;7:241-7.
8. Bronner CE, Baker SM, Morrison PT, Warren G, Smith LG, Lescoe MK, et al. Mutation in the DNA mismatch repair gene homologue hMLH1 is associated with hereditary non-polyposis colon cancer. Nature 1994;368:258-61.

9. Fishel R, Lescoe MK, Rao MRS, Copeland NG, Jenkins NA, Garber J, et al. The human mutator gene homologue MSH2 and its association with hereditary nonpolyposis colon cancer. Cell 1993;75:1027-38.

10. Sakumi K, Shiraishi A, Shimizu S, Tsuzuki T, Ishikawa T, Sekiguchi M. Methylnitrosourea-induced tumorigenesis in MGMT gene knockout mice. Cancer Res 1997;57:2415-8.

11. Tominaga Y, Tsuzuki T, Shiraishi A, Kawate H, Sekiguchi M. Alkylation-induced apoptosis of embryonic stem cells in which the gene for DNA-repair, methyltransferase, had been disrupted by gene targeting. Carcinogenesis 1997;18:889-96.

12. Kawate H, Sakumi K, Tsuzuki T, Nakatsuru Y, Ishikawa T, Takahashi S, et al. Separation of killing and tumorigenic effects of an alkylating agent in mice defective in two of the DNA repair genes. Proc Natl Acad Sci USA 1998;95:5116-20.

13. Japanese Research Society for Gastric Cancer. Japanese classification of gastric carcinoma. First English Ed. 1993; Tokyo: Kanehara.

14. Lauren P. The two histological types of gastric carcinoma: an attempt to reach a histoclinical classification. Acta Pathol Microbiol Scand 1965;64:31-49.

15. Matsukura S, Miyazaki K, Yakushiji H, Ogawa A, Hariyama K, Nakabeppu Y, et al. Expression and prognostic significance of $\mathrm{O}^{6}$ methylguanine-DNA methyltransferase in hepatocellular, gastric and breast cancers. Ann Surg Oncol 2002;8:807-16.

16. Kohya N, Miyazaki K, Matsukura S, Yakushiji H, Kitajima Y, Kitahara $\mathrm{K}$, et al. Deficient expression of $\mathrm{O}^{6}$-methylguanineDNA methyltransferase combined with mismatch-repair proteins $\mathrm{hMLH} 1$ and $\mathrm{hMSH} 2$ is related to poor prognosis in human biliary tract carcinoma. Ann Surg Oncol 2002;9:371-9.

17. Brueckle WM, Limmert T, Brabletz T, Guenther K, Jung A, Hermann $\mathrm{K}$, et al. Origin of microsatellite instability in gastric cancer. Anticancer Res 2000;20:4727-32.

18. Halling KC, Harper J, Moskaluk CA, Thibodeau SN, Petroni GR, Yustein AS, et al. Origin of microsatellite instability in gastric cancer. Am J Pathol 1999;155:205-11.

19. Kulke MH, Thakore KS, Thomas G, Wang H, Loda M, Eng C, et al. Microsatellite instability and hMLH1/hMSH2 expression in Barrett esophagus-associated adenocarcinoma. Cancer 2001; 91:1451-7.

20. Pinto M, Oliveira C, Machado JC, Cirnes L, Tavares J, Carneiro $\mathrm{F}$, et al. MSI-L gastric carcinomas share the hMLH1 methylation status of MSI-H carcinomas but not their clinicopathological profile. Lab Invest 2000;80:1915-23.

21. Chiaravalli AM, Furlan D, Facco C, Tibiletti MG, Dionigi A, Casati B, et al. Immunohistochemical pattern of hMSH2/hMLH1 in familial and sporadic colorectal, gastric, endometrial and ovarian carcinomas with instability in microsatellite sequences. Virchows Arch 2001;438:39-48.

22. Chaves P, Cruz C, Lage P, Claro I, Cravo M, Leitao CN, et al. Immunohistochemical detection of mismatch repair gene proteins as a useful tool for the identification of colorectal carcinoma with the mutator phenotype. J Pathol 2000;191:355-60.

23. Lanza G, Gafa R, Maestri I, Santini A, Matteuzzi M, Cavazzini L. Immunohistochemical pattern of MLH1/MSH2 expression is related to clinical and pathological features in colorectal adenocarcinomas with microsatellite instability. Mod Pathol 2002;7:741-9.

24. Oliveira C, Seruca R, Seixas M, Simoes MS. The clinicopathological features of gastric carcinomas with microsatellite instability may be mediated by mutations of different target genes. Am J Pathol 1998;153:1211-9.

25. Leung SY, Yuen ST, Chung LP, Chu KM, Chan ASY, Ho JCI. hMLH1 promoter methylation and lack of hMLH1 expression in sporadic gastric carcinomas with high-frequency microsatellite instability. Cancer Res 1999;59:159-64. 
26. Bevilacqua RA, Simpson AJ. Methylation of the hMLH1 promoter but no hMLH1 mutations in sporadic gastric carcinomas with high-level microsatellite instability. Int J Cancer 2000; 87:200-3.

27. Endou Y, Tamura G, Ajioka Y, Watanabe H, Motoyama T. Frequent hypermethylation of the hMLH1 gene promoter in differentiated-type tumors of the stomach with the gastric foveolar phenotype. Am J Pathol 2000;157:717-22.

28. Esteller M, Hamilton SR, Burger PC, Baylin SB, Herman JG. Inactivation of the DNA repair gene O6-methylguanine-DNA methyltransferase by promoter hypermethylation is a common event in primary human neoplasia. Cancer Res 1999;59:7937.

29. Fleisher AS, Esteller M, Tamura G, Rashid A, Stine OC, Yin J, et al. Hypermethylation of the hMLH1 gene promoter with microsatellite instability in early human gastric neoplasia. Oncogene 2001;20:329-35.

30. Herman JG, Umar A, Polyak K, Graff JR, Ahuja NJ, Issa JP, et al. Incidence and functional consequences of hMLH1 promoter hypermethylation in colorectal carcinoma. Proc Natl Acad Sci USA 1998;95:6870-5.

31. Kang GH, Shim YH, Ro JY. Correlation of methylation of the hMLH1 promoter with lack of expression of hMLH1 in sporadic gastric carcinomas with replication error. Lab Invest 1999;79:9039.

32. Kang GH, Shim YH, Jung HY, Kim WH, Ro JY, Rhyu MG. CpG island methylation in premalignant stages of gastric carcinoma. Cancer Res 2001;61:2847-51.
33. Qian XC, Brent TP. Methylation hot spots in the 5' flanking region denote silencing of the $\mathrm{O}^{6}$-methyguanine-DNA methytransferase gene. Cancer Res 1997;57:3672-7.

34. Smith SC, Karran P. Epigenetic silencing of the DNA repair enzymes $\mathrm{O}^{6}$-methylguanine-DNA methytransferase in Mexhuman cells. Cancer Res 1992;52:5257-63.

35. Toyota M, Ahuja N, Toyota MO, Herman JG, Baylin SB. Issa JP. $\mathrm{CpG}$ island methylator phenotype in colorectal cancer. Proc Natl Acad Sci USA 1999;96:8681-6.

36. Ueki T, Toyota M, Sohn T, Yeo CJJ, Issa JP, Hruban RH, Goggins M. Hypermethylation of multiple genes in pancreas adenocarcinoma. Cancer Res 2000;60:1835-9.

37. Watts GS, Pieper RO, Costello JF, Peng YM, Dalton W, Futscher BW. Methylation of discrete regions of the $\mathrm{O}^{6}$-methyguanine DNA methyltransferase (MGMT) $\mathrm{CpG}$ island is associated with heterochromatinization of the MGMT transcription start site and silencing of the gene. Mol Cell Biol 1997;17:5612-9.

38. Gerson SL, Trey JE, Miller K, Berger NA. Comparison of O ${ }^{6}-$ alkylguanine-DNA alkyltransferase activity based on cellular DNA content in human, rat and mouse tissue. Carcinogenesis 1986;7:745-9.

39. Wani G, Wani AA, D’Ambrosio SM. Cell type-specific expression of $\mathrm{O}^{6}$-alkylguanine-DNA alkyltransferase gene in normal human liver tissue as revealed by in situ hybridization. Carcinogenesis 1993;14:737-41.

40. Deng D, Xin H. Formation of N-(nitrosomethyl) urea in stomachs of experimental pigs and human volunteers given fish sauce in vivo. J Agric Chem 2000;48:2495-8. 